\title{
Modern Developments in Defense Education
}

\author{
Jim Barrett *
}

\section{Motivation}

The first version of this paper was written for the members of a NATO-sponsored Expert Team, prior to one of the in-country visits described below. A description of defense education would seem to be unnecessary for a group of experts, who were all very familiar with the enterprise of military training and education. Perhaps. Nonetheless, there have been significant developments over the last decade or so, and there may well be some differences of opinion among us on the importance or the future impact of some of these changes. Moreover, our understanding of defense education is so strongly influenced by our very different national experiences that we may not have an accurate sense of the larger picture. It was with these caveats in mind that the earlier version of this essay was written, in order to test our assumptions about how these new developments will affect defense education structures and systems, to provoke reaction, and thereby to serve as a basis for the team's deliberations. This paper is offered in that same spirit; comments, criticisms, and corrections will be welcome.

\section{Modern Currents}

The last fifteen years have seen remarkable growth and expansion in the area of defense education. The training apparatus that prepares armed forces for conflict is now seen as something more - an important educational system for the nation, and an important forum for multi-national cooperation on peace and security. Of course, the training of forces for armed conflict remains the core mission of any military training and education system; that fact alone distinguishes defense education from all other educational systems.

But warfare has changed, and modern armies are responsible for much more than the management of violence. Those of us who are in the business of military training and education have seen remarkable changes in the education of officers (and also of NCOs) in response to the modern perception of war as a broader spectrum of more complex conflicts. Words like stabilization and reconstruction have become standard parts of the vocabulary of defense education. Soldiers are expected to be knowledgeable about underlying political and cultural issues and to be interoperable, not just with the forces of allies, but also with civilian governmental and even non-governmental organizations. For the West, the current deployments in Iraq and Afghanistan daily bring important lessons for the form and content of defense education in the new security en-

\footnotetext{
Dr. Jim Barrett was Co-chair of the Education for Reform Working Group of the Partnership for Peace Consortium from 2006 until 2008. He is the former Director of Learning and Innovation at the Canadian Defence Academy and former Vice Principal of the Royal Military College of Canada. He is grateful for helpful conversations with Fred Labarre, David Emelifeonwu, and John Berry.
} 
vironment. For newly independent and small states, on the other hand, a variety of difficult and complex unresolved conflicts closer to home can be expected to dominate thinking about defense and security for years to come. Defense education is a longterm investment, and its impact will only become clear over several years. Much of that future will depend on how we design our educational systems today.

The preeminent new developments in defense education include:

- Substantially enhanced academic standards

- The growth in continuing professional military education

- International collaboration.

All of these are enabled and frequently stimulated by developments in distance learning, distributed learning, and e-learning, which I will refer to simply by the collective acronym DL. The transformative power of DL should not be underestimated, but neither should it be taken for granted. The use and application of these forms of learning is highly dependent on national culture and the state of local development.

\section{Enhanced Academic Standards}

Since the end of the Cold War there has been an almost universal enthusiasm for increased academic standards in our defense institutions. The impact is evident at all three institutional levels: the military academy, the staff college, and the national defense college. The growing importance of academic standards has led to a vision of the staff college in particular as a post-graduate institution, and to the development of new masters' degrees in military science. This has in turn given the military academy increased importance. As staff colleges and national defense colleges seek to meet the demands of higher academic standards, they find many of the scholars needed to implement these more rigorous measures in the faculty of the military academy. These professors and defense scholars, who are typically engaged in the military education of cadets, are an important engine of defense education. This may be the strongest argument for the coordinated oversight and management of the three institutional levels as a coherent system. Perhaps equally important, there are now increased linkages between military academies and colleges and civilian universities and colleges. In part, this growth in civilian-military educational cooperation reflects a growing interest in the civilian academic realm in matters of national defense and security. That is good news, for universities are among the most stable and influential of a nation's institutions.

For European staff colleges, the Bologna Process sets a reasonable and achievable common standard for what might be termed a "professional" masters' degree, and this has pushed some staff colleges to acquire university status. There are indications of a parallel Erasmus militaire initiative more directly rooted in the defense academies, which seeks to foster the exchange of officers, instructors, and curricula as a means to increase interoperability and to foster a common defense and security culture in Europe. One suspects that, in time, a de facto global academic standard will develop for staff colleges, and even national defense colleges. The challenge will be to preserve 
the essential military character of staff college instruction while accommodating academic processes and standards. This will demand thoughtful compromise by both academic and military authorities, and can be expected to take some time.

\section{Continuing Professional Military Education}

The need for continuing professional military education arises in part from the transition from the Cold War, and in part from the emergence of new, broader models of warfare. All of these changes place a formidable learning burden on the modern officer. There is simply not enough time to include all the required curricula in existing residential courses, nor is it efficient to learn all that new material out of context or in situations that are too far removed from operational experience. As a result, we see the emergence of hybrid programs, where part of a required course is provided in residence, and the remainder is offered by DL. Well-designed hybrid programs draw strongly from the experience of the students. In some cases, the entire command and staff qualification can be acquired by DL. These new modalities of program delivery are proving to be useful for regular forces, and particularly so for the reserves. They work best when introduced as part of a coherent defense education structure and accompanied by appropriate policies supported by senior authority.

One particularly challenging new element is the increased need for inter-agency professional development. The so-called comprehensive approach-drawing on the capacities of defense, diplomacy, and development - has attracted a fair bit of attention and stimulated much debate that should in time produce some well-designed interagency education programs. We now find more civilian students at the staff and national defense colleges, as well as some entirely new courses designed for public servants and other civilians. Perhaps not surprisingly, this is more prevalent in the emerging democracies of the East than in the established ones of the West. More effort is needed in this regard, although it may not be simple. The challenge arises not only from the profound cultural divide between the military and civilian worlds, but also from the asymmetry of resources and organizational talent available to military and civilian organizations. To be truly effective, we will need multi-national, inter-agency education, which will by definition confront us with more and greater cultural and capability gaps that will need to be spanned.

\section{International Collaboration}

Long-term defense reform starts with defense education, and defense education reform is a fully shared enterprise, where the newly independent states are the key players. They, after all, have the greatest investment in regional security, and they have the best understanding of their regions' politics and culture. The challenge is to ensure that these individual national and regional views are not overwhelmed by Western perspectives and priorities. It is true that the dominant models of modern defense education are Western, but some of the best thinking in defense education reform can be found in the newly independent states. It may be that those states are more focused on preparing their armies for the defense of the motherland, but defense education is fully compatible with this mission, offers better prospects for long-term stability, and is not very ex- 
pensive. Defense education addresses the key strategic questions of how the defense and security of states can be achieved cooperatively, using the timeless tools of the academy: study, debate, and teaching. It can only succeed with the active participation of the regional players, with the cooperation of the West. How best might we promote a balanced dialogue?

The answer may lie in the Defense Institution Building initiative articulated at the 2004 Istanbul Summit. Encouraged by NATO and the Partnership for Peace (PfP), and by the United States and other sponsoring nations, the military and civilian academics, educators, and administrators of our military academies and defense academies have engaged in a collaborative PAP-DIB (Partnership Action Plan on Defense Institution Building) activity, known within the PfP Consortium as the Defense Education Enhancement Project, or DEEP. This project has three major components. The first is the development of a Reference Curriculum, and the second is an Educators' Forum. Both these activities are relatively well underway. The third component is a series of incountry visits designed to assist partner nations with the development of their defense education systems in support of an Individual Partner Action Plan (IPAP) or a Membership Action Plan (MAP). There have already been a number of in-country visits, but this activity is less well defined than the other two, and we are still very much in a learning mode. It will be important to assess and report on the visit process itself so that, over time, an agreed approach and shared expectations will emerge.

The main efforts of international cooperation in defense education are aimed at providing support to the defense colleges of new and emerging democracies through the PAP-DIB/DEEP activities. While the academic products of these institutions are important, the great prize is the interconnected, supportive human network that will sustain not only defense education but also broader contact and dialogue between nations. That support network is, by its design, balanced to ensure that the voices of the reforming states will govern the process and pace of change. The new Reference Curriculum is the result of this kind of collaboration. The best examples of its early application are not simple reflections of the printed document, but new and independent work done in-country and informed by the intellectual discourse that lies at the heart of PAP-DIB.

The PAP-DIB Reference Curriculum is a construct familiar to any academic. It is neither a template nor a doctrine, but rather an assembly of ideas designed to stimulate thought and debate. There are three main themes within the curriculum: Public Administration and Governance; Defense Management and Economics; and Ethics and Leadership. The contributing scholars are drawn from three geopolitical areas: NATO/PfP sponsoring nations, nations who have lived the transformation from the Soviet bloc to national independence, and new Partner nations. The support network can therefore be roughly described as a $3 \times 3 \times 3$ matrix, with one axis representing content, the second representing experience or national context, and the third axis representing the three activities of content development, educators' workshops, and incountry visits. It is possible for any nation, regardless of its geopolitical power or stage of development, to participate profitably within this general framework. 


\section{Conclusion}

It is not possible to predict with any certainty what kinds of warfare today's young lieutenants will face when they become colonels and generals. Climate change and environmental decay will bring new conflicts, which will require new means of resolution. But over our lifetimes and in our many nations we have accumulated a rich body of experience and have gained many insights. Drawing on our collected knowledge, we have much to teach each other. Some of the most interesting and innovative developments in defense education can be found in the newer democracies, which are often less constrained by old habits and old assumptions. The PAP-DIB/DEEP project gives us the framework and the tools to learn together, to debate our ideas, and to share our wisdom. We have an opportunity now to build on that framework, to extend it and, most of all, to exploit it for our national and at the same time our mutual benefit. 